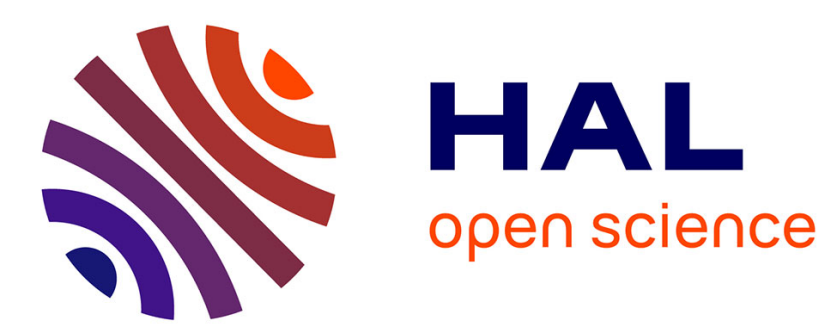

\title{
Creative potential in educational settings: its nature, measure, and nurture
}

\author{
Baptiste Barbot, Maud Besançon, Todd Lubart
}

\section{To cite this version:}

Baptiste Barbot, Maud Besançon, Todd Lubart. Creative potential in educational settings: its nature, measure, and nurture. Education 3-13, 2015, 43 (4), pp.371-381. 10.1080/03004279.2015.1020643 . hal-01392522

\section{HAL Id: hal-01392522 \\ https://hal.parisnanterre.fr/hal-01392522}

Submitted on 9 Nov 2016

HAL is a multi-disciplinary open access archive for the deposit and dissemination of scientific research documents, whether they are published or not. The documents may come from teaching and research institutions in France or abroad, or from public or private research centers.
L'archive ouverte pluridisciplinaire HAL, est destinée au dépôt et à la diffusion de documents scientifiques de niveau recherche, publiés ou non, émanant des établissements d'enseignement et de recherche français ou étrangers, des laboratoires publics ou privés. 
Creative Potential in Educational Settings: its Nature, Measure, and Nurture

\author{
Baptiste Barbot ${ }^{1,2}$ \\ Maud Besançon ${ }^{3}$ \\ Todd Lubart ${ }^{4}$
}

${ }^{1}$ Pace University, Department of Psychology, New York, USA

${ }^{2}$ Yale University, Child Study Center, New Haven, USA

${ }^{3}$ Université Paris Ouest, Nanterre, France

${ }^{4}$ Université Paris Descartes, LATI, Paris, France

\title{
Author Notes.
}

We thank Jessica Harlow for editorial assistance in the preparation of this manuscript.

Correspondence regarding this article should be addressed to Baptiste Barbot; Pace University, Department of Psychology; 41 Park Row; New York, NY, 10038; Tel: (+1) 212-346-1903; Fax: (+1) 212-346-1618; Email: bbarbot@ pace.edu 


\begin{abstract}
Although creativity is considered one of the key " $21^{\text {st }}$ century skills", this ability is still often misunderstood. Persistent conceptual and methodological barriers havelimited educational implications. This article reviews and discusses the three critical issues of "nature", "measure", and "nurture" of creative potential in educational settings. A current perspective on the nature of creative potential is presented. In contrasts to a classic, but inaccurate " $g$-factor view" of creativity, this perspective emphasizes a multidimensional and partly domain-specific view, upon which new assessment tools can be developed. Based on a more comprehensive evaluation of a child's creative potential, educational programs tailored to a child's strengths and weaknesses can be offered. These perspectives are discussed in light of current findings in the field.
\end{abstract}




\section{CREATIVE POTENTIAL IN EDUCATIONAL SETTINGS}

Creative Potential in Educational Settings: its Nature, Measure, and Nurture

Creativity is increasingly recognized as a valuable asset for individuals in their daily problem solving and their professional careers, that contributes to personal and societal development (Besançon, Lubart, \& Barbot, 2013; Lubart, Zenasni, \& Barbot, 2013). As one of the four key " $21^{\text {st }}$ century skills" (together with critical thinking, collaboration, and communication), creativity has received increasing attention in the fields of psychology and education since the 1950's. Despite over half a century of systematic research on this topic, this ability is still incompletely understood. As a result, developing children's creativity in educational settings is a complex endeavor. First, it requires that the nature of the construct of creativity be consensually understood by psychologists, educators, teachers, and the scientific community. Second, it supposes that instruments measuring accurately this construct in children be available. Third, interpretations made from creativity test scores should lead to informed decision in terms of orientation, and accurate implementation of creativity learning in the classroom. This article reviews anddiscusses these three major issues of nature, measure, and nurture in terms of implications in educational settings.

\section{The Nature of Creative Potential}

In the fields of Education and Psychology, creativity is often defined as the ability to produce original and valuable work that fits within particular task or domain constraints (Runco \& Jaeger, 2012; Stein, 1953; Sternberg \& Lubart, 1995). Compared to classical intelligence focusing on analytic ability, knowledge, and expert resolution of common problems with defined solutions, creativity concerns generating new, previously unknown ideas and behaviors in novel situations or treating familiar situations in new ways (Sternberg, 1985). Another important 


\section{CREATIVE POTENTIAL IN EDUCATIONAL SETTINGS}

distinction between creativity and intelligence is that contrary to general intelligence (operationalized by the $g$-factor or IQ), creativity does not represent a unitaryentity (Barbot \& Tinio, in press). If individual differences exist in the outcomes of one's "potential" for creativity, much evidence in the field has pointed to the multifaceted and partly domain-specific nature of creativity: Multifaceted, because a large set of resources come into play in creative work, and the resources needed and their combination may vary according to the specific demands of a particular creative work; Domain-specific, because most people have only a limited set of resources that "fits" the optimal set and combinations of skills required in a given creative outlet, and it is therefore not likely that a person will show achievements across multiple creative tasks.

Hence, to understand the nature of creativity, it is first useful to distinguish between creative potential, creative accomplishment, and creative talent (Barbot \& Lubart, 2012a; Besançon et al., 2013). Creative potential is a latent ability to produce original, adaptive work, which is part of an individual's "human capital” (Walberg, 1988). It results from a person's unique combination of resources coming into play in creative work, including aspects of motivation, cognition, and personality(Lubart, 1999; Lubart et al., 2013; Sternberg \& Lubart, 1995). Specifically, this unique combination results in multiple potentials for creativity (ranging from low to high potential) depending on its fit between one's resources and the various creative tasks demands (e.g., Lubart et al., 2013). Importantly, a person’s potential may lead to achievement if that person has the opportunity to do so. Whereas intellectual ability often results in academic success, creative potential is best accomplished in original and unique outputs, recognized as valuable in a domain-based context. Therefore, creative achievement refers to the actual production of a creative output that has been recognized as creative by some audience. Finally, creative talent refers to the tendency to produce creative work on repeated 


\section{CREATIVE POTENTIAL IN EDUCATIONAL SETTINGS}

occasions(Besançon et al., 2013).Given that exceptional contributions of child prodigy are extremely rare, most teachers, educators, and advisers who are interested in "creativity" in primary and middle schooling-age are in fact most often interested in the construct of "creative potential" rather than to creative achievement or creative talent.

According to componential approaches to creativity, creative potential reflects the confluence of several distinct, but interrelated resources(Sternberg \& Lubart, 1995). Person-level resources include biological and genetic factors (Barbot, Tan, \& Grigorenko, 2013; Kaufman, Kornilov, Bristol, Tan, \& Grigorenko, 2010), aspects of cognitionsuch as divergent thinking (Guilford, 1950); or metaphorical thinking (Tan, Barbot, Mourgues\&Grigorenko2013), and aspects of conation (personality, motivational and emotional factors) such as the willingness to take risks and be open to new ideas and experiences, while tolerating ambiguous situations and stimuli (Besançon et al., 2013). Other person-level resources include task-relevant knowledge that are necessary in each specific content area such as creative writing (Barbot, Tan, Randi, Santa-Donato, \& Grigorenko, 2012), musical composition (Barbot \& Lubart, 2012b), or managerial creativity (Caroff \& Lubart, 2012). Finally, environmental-level resources refer to aspects of culture, time and place (physical and/or socio-environmental settings; e.g., Barbot \& Tinio, in press).

The presence of each of these resources and their particular combinationwithin each person explain the individual differences in creative potential across domains and tasks (Lubart, 1999; Sternberg \& Lubart, 1995). Indeed, a person's creative potential for a given domain or task varies according to the nature and combination of the resources needed in that particular outlet (Barbot \& Tinio, in press; Lubart et al., 2013). As an illustration, a child may show high potential in poetry composition, average potential in creative fiction composition, and low potential in 


\section{CREATIVE POTENTIAL IN EDUCATIONAL SETTINGS}

musical composition. This heterogeneity is expectedbecause these creative outlets involve a somewhat specific set of resources (not only task-relevant knowledge): for example, associative and metaphorical thinking might be crucial resources for poetry composition, whereas perseverance and imagination might be the most important resources for writing creative fiction (Barbot et al., 2012; Barbot et al., 2013; Barbot \& Tinio, in press; Tan et al., 2012).

Hence, the different nature of these creative outlets entails a different set of person-level resources that must come into play in a particular way to lead to high creativity outcomes. Extending this idea, the child showing high potential in poetry composition may also show a high potential inslam poetry because these outletsbuild upon a very similar set of resources.In other words, individuals show similar levels of creative potential in outlets that are highly similar. The extent of similarity between two tasks is defined by (1) the nature of the resources solicited in each creative outlet, (2) the extent to which each resource is solicited, and (3) the way in which the resources come into play during the creative process (Lubart et al., 2013). As a result, it is increasingly acknowledged that creative potential represents simultaneously a domain-general ability (set of resources that is involved in the creative work across domains, regardless of the specific nature of the task), a set of domain-specific abilities (domain relevant resources that are needed across creative tasks within a particular domain), and a set of taskrelevant abilities (resources that are uniquely associated with a given creative outlet of interest); (e.g., Baer, 1998; Baer \& Kaufman, 2005; Barbot \& Tinio, in press; Dietrich, 2007; Lubart, 1999; Lubart \& Guignard, 2004). Because eachcreative outlet may be characterized as partially similar to other outlets and as partially specific, it is most useful to conceive a person's creative potential in terms of a set of potentialities (Lubart et al., 2013). 


\section{CREATIVE POTENTIAL IN EDUCATIONAL SETTINGS}

There is much evidence supporting this conceptualization of creative potential. In studies of "generic samples", low-to medium-size correlations between measures of creative potential from different domains are usually reported (correlationsin the .10 to .30 range; Carson, Peterson, \& Higgins, 2005; Lubart \& Guignard, 2004; Plucker \& Runco, 1998; Silvia, Kaufman, \& Pretz, 2009). Further, only moderate correlations between measures of creative potential from the same domains were also reported (Baer, 1994), outlining the important contribution of taskrelevant resources in a given creative outlet. Similarly, in studies of eminent creators (called BigC creativity;Kaufman \& Beghetto, 2009) it is usually observed that exceptional levels of creativity in several lines of work in agiven domainare rare, and even more so across more than one domain (Gray, 1966).

In sum, creative potential refers to a particular combination of individual and contextual resources coming into play in creative work (including aspects of motivation, cognition, and personality). Depending on the fit between a given task requirements and a person's multivariate profile of resources, individual differences in creative outcomes will emerge. Although the creativity of these outcomes will vary across individuals (with levels presumably following a normal distribution), this doesnot mean that creativity represents a generalized (or unitary) entity or trait (Barbot \& Tinio, in press). Being creative in a given outlet will rely not only on a set of domain-general, domain-specific, and task relevant resources underlying creative potential in that particular outlet, but also on the ability to transform one's potential into real-world work that has been recognized as creative by the social world in a given time and place.

\section{Evaluating Creative Potential in School-age Children}

The multifaceted and partly domain-specific view of creative potential outlined above contrasts with a classic, yet inaccurate "g-factor view" of creativity in many respects (Barbot 


\section{CREATIVE POTENTIAL IN EDUCATIONAL SETTINGS}

\&Tinio, in press). Indeed, many studies have made inferences about creativity as a generalized construct while using very specific tasks (in highly specificcontent areas), although there is limited evidence for the domain-generality of creativity.However, at the individual level, it would be inaccurate to make inferences on a child's creative potential based on a limited set of tasks, sampling a narrow range of resources involved and domains of creative endeavors. Therefore, the issue of assessment of creative potential is critical both for research and practical considerations such as testing the impact of educational contexts on creativity, or training a child's creativity.

Currently, there are three main objectives of creative potential assessment in educational settings: (1) to identify the potential of children to guide them in an appropriate and tailored way; (2) to identify the average level of potential for creativity of a whole group of students (e.g., classroom level, school level, nation-level) to conduct comparisons between groups and gauge the effects of training programs, alternative pedagogies or culture on creativity; and (3), to monitor change in creative potential under "natural" development or in response to a training or educational program. Regardless of the specific objective, creative potential should be measured by assessment tools tapping into the multidimensionality of the construct (Barbot, Besançon, \& Lubart, 2011). Indeed, as outlined above, the construct of creative potential is viewed as multifaceted, partly domain-specific, and is thought to be trainable. In line with this, several domain-specific training programs have been developed with the objective to enhance creative thinking at elementary and secondary school levels in a number of ways (e.g., Besançon \& Lubart, 2008; Besançon et al., 2013; Lynch \& Harris, 2001; Starko, 1995). However, most programs have monitored change in creative potential with instruments that do not capture its multidimensionality and domain-specificity. 


\section{CREATIVE POTENTIAL IN EDUCATIONAL SETTINGS}

To date, two main paths to the measurement of creative potential have been used (Barbot et al., 2011; Lubart et al., 2013). One is resource-based (or analytic) and examines the fit between an individual's resources and creative task demands, whereas the second is outcomebased (or "holistic") and captures an individual level of creative potential, using task performance in situations simulating various aspects of the creative work. Among numerous creative potential assessments that were developed to date, many resource-based approaches have focused on a limited set of components thought to contribute to creativity (Barbot et al., 2011). After Guilford (1950), this approach to creativity assessment was prevalent with the underlying view of creativity as a general and unidimensional construct. Often, it has led researchers and practitioners to use measures of a specific resource involved in creative potential (in particular, divergent thinking), and interpreted test scores as pure indicators of a child's "general" creativity, without distinction of the resource, type of task, or domain of creative expression (Barbot et al., 2011).

In related work (Barbot et al., 2011; Lubart et al., 2013), we have reviewed measures of the person-level resources that are commonly used in this general and unidimensional view ( $g$ factor view) of creative potential. For the cognitive aspects, divergent thinking tests such as the Torrance Tests of Creative Thinking (1966) or the Wallach and Kogan tests (1965) have been commonly used. These standardized tasks evaluate the capacity of the children to generate, in a limited time, many ideas from a simple starting point. This starting point can be a hypothetical situation (e.g., "What if?" -type questions), a graphic stimulus (e.g., supplement as many incomplete graphicshapes as possible by generating original drawings using the graphic stimulus) or an object (e.g., propose various alternative uses of a familiar object). Individual differences in the divergent thinking production generated in response to the stimuli are 


\section{CREATIVE POTENTIAL IN EDUCATIONAL SETTINGS}

quantified according to the number of responses (ideational fluency), their variety (ideational flexibility) and their relative (i.e., norm-referenced) infrequency (originality). Divergent thinking is essential for creativity because generating numerous ideas and considering alternative pathways of research increase the probability of finding an original and adapted idea (Lubart, Besançon, \& Barbot, 2011).

Regarding conative resources (Selby, Shaw, \& Houtz, 2005), essential features typically measured include perseverance and motivational aspects (Amabile, Hill, Hennessey, \& Tighe, 1994), creative personality-based characteristics (e.g., tolerance to ambiguity,openness to new experiences, individualism, risk-taking or psychoticism), as well as aspects of creative selfbeliefs such as creative self-efficacy (e.g., Beghetto \& Kaufman, 2011; Karwowski \& Barbot, in press). Although these resources may apply to a range of creative outlets (measures of these characteristics generally do not apply to a specific content area, but are thought to be conductive of creativity regardless of the domain of creative outcome), it is to be noted that some domainand even task-relevant demands might require more or less of each component. For example, a given creative task such as writing a creative fiction might require more intense commitments, and therefore, factors such as perseverance and intrinsic motivation might become more salient to lead to highly creative outputs.

With regard to outcome-based (or "holistic") measures of creative potential in educational settings, children are typically presented with a standardized task leading them to produce a single creative output such as a story, a drawing, or a musical composition, (e.g., (Barbot \& Lubart, 2012b; Jellen, 1986). This assessment situation engages all of the person-level resourcesto lead to a creative production in the domain of interest. The productions resulting from the tasks are then scored by domain-relevant judges (Kaufman, Evans, \& Baer, 2010; 


\section{CREATIVE POTENTIAL IN EDUCATIONAL SETTINGS}

Priest, 2006) using the consensual assessment technique (CAT;Amabile, 1982). This technique supposes that judgments about creativity imply a social consensus: if independent domainrelevant judges "classify" the same productions in the same way with regard to their level of creativity, it is possible to conclude that raters have identified the same quality (that is, creativity). When a consensus is statistically reached (i.e, acceptable inter-rater agreement) the scores given by each judge to each production can be averaged to derive a composite score. Accordingly, the extent to which a person produces work evaluated as creative in this context, compared to other individuals who have completed the same task is a measure of the person's creative potential (Lubart et al., 2013).

Combining both pathways to the evaluation of creative potential (resource-based and outcome-based), we developed a new measure to assess creative potential in children and adolescents: the Evaluation of Potential Creativity (EPoC; Lubart et al., 2011). This test battery measures two key creative thinking-process clusters (divergent-exploratory and convergentintegrative) in verbal-literary and graphic domains (with forthcoming extensions in other domains such as social problem-solving, scientific and musical domains). Building upon Guilford (1950) and others, the divergent-exploratory mode of thinking refers to the process of expanding the range of solutions in creative problem solving. The convergent-integrative thinking process cluster refers to the activity of combining, integrating or synthesizing elements in new ways, and encompasses some convergent operations such as "synthesis" and "evaluation of ideas" (Cropley, 2006; Osborn, 1953).

To both reliably measure the thinking-process clusters in each domain of creative work and limit the over-representation of task-specific resources in the resulting scores, EPoC consists of two tasks engaging divergent-exploratory thinking processes and two tasks involving 


\section{CREATIVE POTENTIAL IN EDUCATIONAL SETTINGS}

convergent-integrative thinking processes in each domain. As a result, EPoC consists currently of eight subtest yielding four composite score measuring each "Thinking-Process-Domain unit", namely, "Divergent Graphic" (DG) (e.g., a graphic shape is provided and the child must make as many drawings as possible to complete the shape), "Integrative Graphic" (IG) (e.g., a set of images of objects are provided and the child must produce a complete drawing using at least four of the eight objects provided), "Divergent Verbal" (DV) (e.g., generate many endings to a story beginning), and "Integrative Verbal" (IV) (e.g., generate a complete story based on descriptions of several fictional characters provided). Each task is standardized in terms of time limitation, instructions, and material provided, and two alternate forms areavailable (Form A and Form B) in order to use the battery in test-retest settings (e.g., pre- and post- intervention).

EPoC's structured framework allows a child's profile of creative potential to be examined, outlining the relative strengths and weaknesses of the child in each Thinking-ProcessDomain unit (DG, IG, DV, IG). Therefore, EPoC operationalizes creative potential as simultaneously "domain-specific" and "thinking-process specific", resulting in multiple indicators of creative potential that have been found to be relatively independent (Lubart et al., 2011).

\section{Nurturing Creative Potential in Educational Settings}

Creative potential is not a "fixed" entity and each of the person-level resources of creative potential outlined above develop and evolve over time, through "natural" or targeted interactions within the school, home, or work context (Besançon et al., 2013). One of the most influentialmicroenvironments for the development of creativity is indeed the school environment (Mourgues, Barbot, Tan, \& Grigorenko, 2014). The impact of this environment on the development of creativity has been examined in some studies that contrasted traditional school 


\section{CREATIVE POTENTIAL IN EDUCATIONAL SETTINGS}

settings with alternative pedagogy settings. For example, in multiple cultures, alternative pedagogies such as Montessori and Freinet lead to higher creative potential in students compared to those exposed to traditional pedagogy (Allodi, 2010; Besançon \& Lubart, 2008; Besançon et al., 2013; Heise, Böhme, \& Körner, 2010). Hence, school environment can affect the development of creativity by encouraging it or discouraging it, either implicitly or explicitly (Mourgues et al., 2014). As a result, some school contexts are presumably favoring creativity more than others, and they may, to different degrees, invite children to express their cognitive, conative and affective resources underlying creative potential. What are the school-level, Classroom-level, and teacher-level factors that might explain this classic difference?

In a review of over 200 articles, Davies and colleagues (Davies et al., 2013) identified characteristics of the school environments that promote creative skills in children including aspects of the physical environment, availability of resources/materials, pedagogical environment, play-based learning, and relationships between teachers and learners. Specifically, two general aspects of the school environment seem most influential: (1) the structure, atmosphere, and operation of the classroom, and (2) the attitude of the teacher toward creativity. At the classroom level, assessment, limitation of choices, pressure to conform, competition, and rote learning can compromise creativity development (Beghetto, 2005; Kudryavtsev, 2011). For example, if a climate of criticism and normative behavior dominates in a classroom, children will integrate that creativity is "not part of the program", will not be rewarded, and children may even be seen as disruptive (Besançon et al., 2013). This classroom climate is tightly related to attitudes, practices, and personal characteristics of the teachers.

At the teacher level, there is a distinction between how to teach creatively, versus how to teach creativity (e.g., Craft, 2005; Cremin, Burnard, \& Craft, 2006). It is first important to note 


\section{CREATIVE POTENTIAL IN EDUCATIONAL SETTINGS}

that, by their attitudes and way of being, adults may impact children's development of creative potential in a more general way. High expectations, mutual respect, the modeling of creative attitudes, flexibility, and dialogue are among the most important features of the teacher-learner relationship for creativity (Davies et al., 2013). Hence, teaching for creativity requires not only the teaching of a set of domain specific knowledge and skills, but also a more general attitude encouraging emotional capacity to tolerate uncertainty or take risks (Cremin, 2006b). However, literature on creativity in education has repeatedly reported teachers' difficulties to integrate creativity into the traditional classroom routines. In the western world, Eckhoff (2011) found that pre-service teachers valued creative thinking but were unsure about how to support it in early childhood classrooms. Similarly,Burnard (2008) outlined the challenge of teachers in teaching creativity while meeting demanding requirements for academic performance. In the eastern world, a comparative study of Asian cultures showed that, although teachers believed in the importance of teaching creativity, their attitudes and beliefs about the implementation of creativity learning in the classroom were generally negative (Chien, 2010; Mourgues et al., 2014).

With regard to teaching creativity, based on a comprehensive evaluation of a child's creative potential (such as approached with the EPoC described above), it is possible to derive tailored programs to develop children's creative potential, based on the most salient aspects of their multivariate profile of creative potential. For example, based on empirical studies with EPoC (Lubart et al., 2011), we have identified six typical profiles of children's creative potential including (1) "High potential" (high scores across EPoC indexes), (2) "Low potential" (low scores across EPoC indexes), (3) "Verbal” (strengths in Verbal tasks), (4) "Graphic" (strengths in Graphic tasks), (5) "Divergent" (strengths in Divergent tasks), and (6), "Integrative" (strengths 


\section{CREATIVE POTENTIAL IN EDUCATIONAL SETTINGS}

in Integrative tasks). According to the most salient aspectsof a child's profile, activities can be developed to stimulate the areas of weaknesses. However, it is to be noted that several training program and short-term interventions tailored to stimulate specific thinking processes such as divergent thinking have mainly resulted in mixed outcomes (Russ, 2003). More successful programs have involved efforts to improve children's play skills and agency (Craft, McConnon, \& Matthews, 2012). Using the EPoC's framework, an optimal strategy to improve children's creative potential is to first focus on their strengths to then work on their weaknesses.

When a child shows a strength in a domain (e.g., graphic) it is not always ideal to focus the work directly on a weaker domain (e.g., verbal). However, to transfer from the graphic domain to the verbal domain, it can be useful to work with the child on his own drawings and ask him to develop stories based on these drawings, thus stimulating the verbal aspect. When one of the two thinking process is prevalent (divergent or integrative), the strategy is different because both thinking processes are usually building upon each other in the creative work. It is therefore important to work on the development on both thinking modes. When a child is "integrative", it is useful to work with him on the notion of openness and expanding the range of possibilities. Based on the same activity and instruction, the child could invent a first story, upon which the adult can develop another story using the same elements. Then, the child builds upon the story generated by the adult, to develop a new story.

When a child is "divergent", the difficulty for the child is usually to select one or a few promising ideas in order to develop and elaborate them in a structured way. Building upon the child's strength (generating many ideas), a brainstorming setting can be used to elicit the child's numerous ideas. Then, the child can work on categorizing his ideas in order to lead to "higherorder" ideas that synthesize the ideas classified in the same category. Ultimately, the work can be 


\section{CREATIVE POTENTIAL IN EDUCATIONAL SETTINGS}

focused on the process of idea selection. Ideas that seem most interesting or original can be selected and integrated into a coherent whole. These examples illustrate the importance of considering a differentiated set of resources to identify a child's areas of strengths and weaknesses, which could not be achieved by "unitary" measures of creative potential.

\section{Conclusion}

For creativity to really become one of the " $21^{\text {st }}$ century skills", it has to be understood as a facet of human capital which is multidimensional, partly domain-specific, and can be developed and nurtured. During over half a century, and since the beginning of the systematic study of creativity, measures of creative potential have often relied on a unitary and domaingeneral view that has delayed advances in the nurturing of creativity in educational settings. Indeed, the field has long suffered from the proliferation of assessment techniques showing lack of theoretical grounds and limited educational applications (Barbot et al., 2011; Houtz \& Krug, 1995). Correspondingly, there have been many definitions of the concept, but limited consensus on the nature of creative potential upon which to base the development of new measures (Barbot et al., 2011). One of the most recurrent suggestions to address these conceptual and methodological barriers is to multiply the assessment approaches to yield a more complete picture of an individual's potential for creativity (Barbot et al., 2011; Feldhusen \& Goh, 1995; Fishkin \& Johnson, 1998; Han \& Marvin, 2002; Hunsaker \& Callahan, 1995).

Toward this endeavor, we have developed a new instrument, the EPoC, which aims to provide a comprehensive evaluation of a child's creative potential. Although such multidimensional measures may help to develop new training programs in schools settings, much effort is still needed to understand the trainability of creative potential, its sensitivity to schoolenvironment factors, as well as the conditions and pathways leading to the transformation of 
CREATIVE POTENTIAL IN EDUCATIONAL SETTINGS

one's creative potential into real-world work that is recognized as original and valuable by the social world, in a given time and place. 


\section{CREATIVE POTENTIAL IN EDUCATIONAL SETTINGS}

\section{References}

Allodi, M. W. (2010). Goals and values in school: A model developed for describing, evaluating and changing the social climate of learning environments. Social Psychology of Education, 13(2), 207; 207-235; 235.

Amabile, T. M. (1982). Social psychology of creativity: A consensual assessment technique. Journal of Personality and Social Psychology, 43(5), 997-1013.

Amabile, T. M., Hill, K. G., Hennessey, B. A., \& Tighe, E. M. (1994). The work preference inventory: Assessing intrinsic and extrinsic motivational orientations. Journal of Personality and Social Psychology, 66, 950-967.

Baer, J. (1994). Divergent thinking is not a general trait: A multidomain training experiment. Creativity Research Journal, 7(1), 35-46.

Baer, J. (1998). The case for domain specificity in creativity. Creativity Research Journal, 11, 173-177.

Baer, J., \& Kaufman, J. C. (2005). Bridging generality and specificity: The amusement park theoretical (APT) model of creativity. Roeper Review, 27(3), 158-163.

Barbot, B., Besançon, M., \& Lubart, T. I. (2011). Assessing creativity in the classroom. The Open Education Journal, 4(1), 58-66.

Barbot, B., \& Lubart, T. I. (2012a). Adolescence, créativité et transformation de soi.Enfance, 2012(03), 299. doi:10.4074/S0013754512003059

Barbot, B., \& Lubart, T. I. (2012b). Creative thinking in music: Its nature and assessment through musical exploratory behaviors. Psychology of Aesthetics, Creativity, and the Arts, 6(3), 231-242. doi:10.1037/a0027307

Barbot, B., Randi, J., Tan, M., Levenson, C., Friedlaender, L., \& Grigorenko, E. L. (2013). From perception to creative writing: A multi-method pilot study of a visual literacy instructional approach. Learning and Individual Differences, 28, 167-176.

doi:10.1016/j.lindif.2012.09.003

Barbot, B., Tan, M., \& Grigorenko, E. L. (2013). The genetics of creativity: The generative and receptive sides of the creativity equation. In O. Vartanian, A. Bristol \& J. C. Kaufman (Eds.), The neuroscience of creativity (pp. 71-93) MIT Press.

Barbot, B., Tan, M., Randi, J., Santa-Donato, G., \& Grigorenko, E. L. (2012). Essential skills for creative writing: Integrating multiple domain-specific perspectives. Thinking Skills and Creativity, 7(3), 209-223. doi:10.1016/j.tsc.2012.04.006

Barbot, B., \& Tinio, P. P. L. (in press). Where is the " $\mathrm{g}$ " in creativity? A specializationdifferentiation hypothesis. Frontiers in Human Neuroscience,

Beghetto, R. A. (2005). Does assessment kill student creativity? The Educational Forum, , 69(3) 254-263.

Beghetto, R. A., \& Kaufman, J. C. (2011). Answering the unexpected questions: Exploring the relationship between students' creative self-efficacy and teacher ratings of creativity. American Psychological Association, 5(4), 342-349. doi:10.1037/a0022834 


\section{CREATIVE POTENTIAL IN EDUCATIONAL SETTINGS}

Besançon, M., \& Lubart, T. I. (2008). Differences in the development of creative competencies in children schooled in diverse learning environments. Learning and Individual Differences, 18(4), 381-389.

Besançon, M., Lubart, T. I., \& Barbot, B. (2013). Creative giftedness and educational opportunities. Educational and Child Psychology., 30(2), 79-88.

Burnard, P. (2008). Creativity and performativity: Counterpoints in british and australian education. British Educational Research Journal, 34(5), 667-682.

Caroff, X., \& Lubart, T. I. (2012). Multidimensional approach to detecting creative potential in managers. Creativity Research Journal, 24(1), 13-20. doi:10.1080/10400419.2012.652927

Carson, S. H., Peterson, J. B., \& Higgins, D. M. (2005). Reliability, validity, and factor structure of the creative achievement questionnaire. Creativity Research Journal, 17(1), 37-50.

Chien, C. -. (2010). Creativity in early childhood education: Teachers' perceptions in three chinese societies. Thinking Skills and Creativity, 5(2), 49-60.

Craft, A. (2005). Creativity in schools: Tensions and dilemmas Psychology Press.

Craft, A., McConnon, L., \& Matthews, A. (2012). Child-initiated play and professional creativity: Enabling four-year-olds' possibility thinking. Thinking Skills and Creativity, 7(1), 48-61.

Cremin, T., Burnard, P., \& Craft, A. (2006). Pedagogy and possibility thinking in the early years. Thinking Skills and Creativity, 1(2), 108-119.

Cremin, T. (2006b). Creativity, uncertainty and discomfort: Teachers as writers. Cambridge Journal of Education, 36(3), 415-433.

Cropley, A. (2006). In praise of convergent thinking. Creativity Research Journal, 18(3), 391404. doi:10.1207/s15326934crj1803_13

Davies, D., Jindal-Snape, D., Collier, C., Digby, R., Hay, P., \& Howe, A. (2013). Creative learning environments in education-A systematic literature review. Thinking Skills and Creativity, 8(0), 80-91.

Dietrich, A. (2007). Who's afraid of a cognitive neuroscience of creativity? Methods, 42(1), 2227.

Eckhoff, A. (2011). Creativity in the early childhood classroom: Perspectives of preservice teachers. Journal of Early Childhood Teacher Education, 32(3), 240-255.

Feldhusen, J. F., \& Goh, B. E. (1995). Assessing and accessing creativity: An integrative review of theory, research, and development. Creativity Research Journal, 8, 231-247.

Fishkin, A. S., \& Johnson, A. S. (1998, Who is creative? identifying children's creative abilities. Roeper Review, 21, 40-46.

Gray, C. E. (1966). A measurement of creativity in western civilization. American Anthropologist, 68(6), 1384-1417.

Guilford, J. P. (1950). Creativity. The American Psychologist, 5, 444-454.

Han, K., \& Marvin, C. (2002). Multiple creativities? investigating domain-specificity of creativity in young children. Gifted Child Quarterly, 46(2), 98-109. 


\section{CREATIVE POTENTIAL IN EDUCATIONAL SETTINGS}

Heise, E., Böhme, E., \& Körner, S. B. (2010). Montessori-orientierter und traditioneller grundschulunterricht: Ein vergleich der entwicklung von rechtschreibung, rechnen, intelligenz und kreativität. Psychologie in Erziehung Und Unterricht, (4), 273-289.

Houtz, J., \& Krug, D. (1995). Assessment of creativity: Resolving a mid-life crisis. Educational Psychology Review, 7(3), 269-300. doi:10.1007/BF02213374

Hunsaker, S. L., \& Callahan, C. M. (1995, Creativity and giftedness: Published instrument uses and abuses. Gifted Child Quarterly, 39, 110-114.

Jellen, H. G. (1986). The TCT-DP (test for creative thinking-drawing production): An instrument that can be applied to most age and ability groups. Creative Child and Adult Quarterly, 11, 138-155.

Karwowski, M., \& Barbot, B. (in press). Creative self-beliefs: Their nature, development and correlates. In J. C. Kaufman, \& J. Baer (Eds.), The cambridge companion to creativity and reason in cognitive development. () Cambridge University Press.

Kaufman, J. C., \& Beghetto, R. A. (2009). Beyond big and little: The four c model of creativity. Review of General Psychology, 13(1), 1-12. doi:doi: 10.1037/a0013688

Kaufman, J. C., Evans, M. L., \& Baer, J. (2010). The american idol effect: Are students good judges of their creativity across domains? Empirical Studies of the Arts, 28(1), 3-17.

Kaufman, A. B., Kornilov, S. A., Bristol, A. S., Tan, M., \& Grigorenko, E. L. (2010). The neurobiological foundation of creative cognition. In J. C. Kaufman, \& R. J. Sternberg (Eds.), (pp. 216-232). New York: Cambridge University Press.

Kudryavtsev, V. T. (2011). The phenomenon of child creativity. International Journal of Early Years Education, 19(1), 45-53.

Lubart, T. I. (1999). Componential models of creativity. In M. A. Runco, \& S. Pritzer (Eds.), (pp. 295-300). New York:NY: Academic Press.

Lubart, T. I., Besançon, M., \& Barbot, B. (2011). Evaluation du potentiel créatif (EPoC). Paris: Editions Hogrefe France.

Lubart, T. I., \& Guignard, J. (2004). The generality-specificity of creativity: A multivariate approach. In R. J. Sternberg, E. L. Grigorenko \& L. Singer (Eds.), Creativity: From potential to realization (pp. 43-56). Washington, DC: American Psychological Association.

Lubart, T. I., Zenasni, F., \& Barbot, B. (2013). Creative potential and its measurement. International Journal of Talent Development and Creativity, 1(2), 41-51.

Lynch, M. D., \& Harris, C. R. (2001). Fostering creativity in children, K-8: Theory and practice. Needham Heights, MA: Allyn \& Bacon.

Mourgues, C., Barbot, B., Tan, M., \& Grigorenko, E. L. (2014). The interaction between culture and the development of creativity. In L. Arnett Jensen (Ed.), The oxford handbook of human development and culture: An interdisciplinary perspective ()

doi:10.1093/oxfordhb/9780199948550.013.16

Osborn, A. F. (1953). Applied imagination. Oxford, England: Scribner's.

Plucker, J. A., \& Runco, M. A. (1998). The death of creativity measurement has been greatly exaggerated. Roeper Review, 21(1), 36-39. 


\section{CREATIVE POTENTIAL IN EDUCATIONAL SETTINGS}

Priest, T. (2006). The reliability of three groups of judges' assessments of creativity under three conditions. Bulletin of the Council for Research in Music Education, (167), 47-60.

Runco, M. A., \& Jaeger, G. J. (2012). The standard definition of creativity. Creativity Research Journal, 24(1), 92-96.

Russ, S. W. (2003). Play and creativity: Developmental issues. Scandinavian Journal of Educational Research, 47(3), 291-303.

Selby, E. C., Shaw, E. J., \& Houtz, J. C. (2005, The creative personality. Gifted Child Quarterly, 49, 300-331.

Silvia, P. J., Kaufman, J. C., \& Pretz, J. E. (2009). Is creativity domain-specific? latent class models of creative accomplishments and creative self-descriptions. Psychology of Aesthetics, Creativity, and the Arts, 3(3), 139-148. doi:10.1037/a0014940

Starko, A. J. (1995). Creativity in the classroom: Schools of curious delight. New York, NY: Longman.

Stein, M. I. (1953). Creativity and culture. Journal of Psychology: Interdisciplinary and Applied, $36,311-322$.

Sternberg, R. J. (1985). Beyond IQ: A triarchic theory of human intelligence CUP Archive.

Sternberg, R. J., \& Lubart, T. I. (1995). Defying the crowd: Cultivating creativity in a culture of conformity. New York: The Free Press.

Tan, M., Barbot, B., Mourgues, C. \& Grigorenko, E. L. (2013). Measuring metaphors: Concreteness and similarity in metaphor comprehension and gifted identification. Educational and Child Psychology, 30(2), 89-100.

Tan, M., Randi, J., Barbot, B., Levenson, C., Friedlaender, L., \& Grigorenko, E. L. (2012). Seeing, connecting, writing: Developing creativity and narrative writing in children. In E. L. Grigorenko, E. Mambrino \& D. D. Preiss (Eds.), Writing: A mosaic of new perspectives, psychology press, new york (pp. 275-291). New York, NY: Psychology Press.

Torrance, E. P. (1966). The torrance tests of creative thinking-norms-technical manual research edition-verbal tests, forms $A$ and B-figural tests, forms $A$ and B. Princeton, NJ: Personnel Press.

Walberg, H. J. (1988). Creativity and talent as learning. In R. J. Sternberg (Ed.), The nature of creativity: Contemporary psychological perspectives (pp. 340-361). Cambridge: Cambridge University Press.

Wallach, M., \& Kogan, N. (1965). Modes of thinking in young children. New York: Holt, Rinehart \& Winston. 